\title{
Femtosecond ultraviolet laser ablation of silver and comparison with nanosecond ablation
}

Christensen, Bo Toftmann; Doggett, B.; Budtz-Jørgensen, C.; Schou, Jørgen; Lunney, J. G.

Published in:

Journal of Applied Physics

Link to article, DOI:

$10.1063 / 1.4792033$

Publication date:

2013

Document Version

Publisher's PDF, also known as Version of record

Link back to DTU Orbit

Citation (APA):

Christensen, B. T., Doggett, B., Budtz-Jørgensen, C., Schou, J., \& Lunney, J. G. (2013). Femtosecond ultraviolet laser ablation of silver and comparison with nanosecond ablation. Journal of Applied Physics, 113(8), [083304]. https://doi.org/10.1063/1.4792033

\section{General rights}

Copyright and moral rights for the publications made accessible in the public portal are retained by the authors and/or other copyright owners and it is a condition of accessing publications that users recognise and abide by the legal requirements associated with these rights.

- Users may download and print one copy of any publication from the public portal for the purpose of private study or research.

- You may not further distribute the material or use it for any profit-making activity or commercial gain

- You may freely distribute the URL identifying the publication in the public portal 


\section{AIP Appilied Physics}

\section{Femtosecond ultraviolet laser ablation of silver and comparison with}

nanosecond ablation

B. Toftmann, B. Doggett, C. Budtz-Jørgensen, J. Schou, and J. G. Lunney

Citation: J. Appl. Phys. 113, 083304 (2013); doi: 10.1063/1.4792033

View online: http://dx.doi.org/10.1063/1.4792033

View Table of Contents: http://jap.aip.org/resource/1/JAPIAU/v113/i8

Published by the AIP Publishing LLC.

\section{Additional information on J. Appl. Phys.}

Journal Homepage: http://jap.aip.org/

Journal Information: http://jap.aip.org/about/about_the_journal

Top downloads: http://jap.aip.org/features/most_downloaded

Information for Authors: http://jap.aip.org/authors

\section{ADVERTISEMENT}

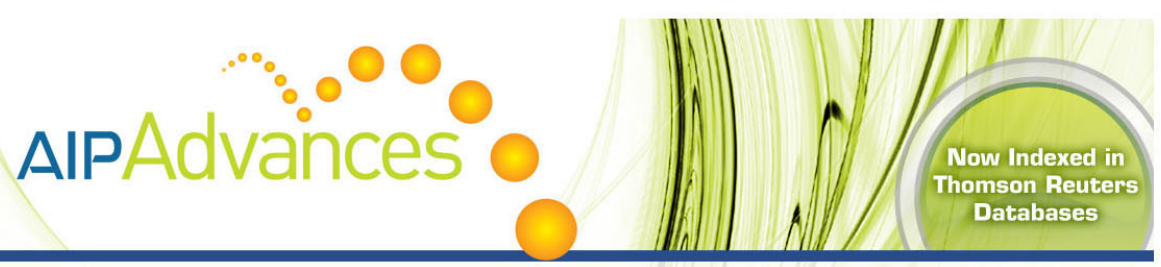

\section{Explore AIP's open access journal: Rapid publication \\ - Article-level metrics \\ - Post-publication rating and commenting}




\title{
Femtosecond ultraviolet laser ablation of silver and comparison with nanosecond ablation
}

\author{
B. Toftmann, ${ }^{1}$ B. Doggett, ${ }^{2}$ C. Budtz-Jørgensen, ${ }^{2}$ J. Schou, ${ }^{1, a)}$ and J. G. Lunney ${ }^{2}$ \\ ${ }^{1}$ DTU Fotonik, Risø Campus, DK-4000 Roskilde, Denmark \\ ${ }^{2}$ School of Physics, Trinity College Dublin, Dublin 2, Ireland
}

(Received 21 November 2012; accepted 29 January 2013; published online 26 February 2013)

\begin{abstract}
The ablation plume dynamics arising from ablation of silver with a $500 \mathrm{fs}, 248 \mathrm{~nm}$ laser at $\sim 2 \mathrm{~J} \mathrm{~cm}^{-2}$ has been studied using angle-resolved Langmuir ion probe and thin film deposition techniques. For the same laser fluence, the time-of-flight ion signals from femtosecond and nanosecond laser ablation are similar; both show a singly peaked time-of-flight distribution. The angular distribution of ion emission and the deposition are well described by the adiabatic and isentropic model of plume expansion, though distributions for femtosecond ablation are significantly narrower. In this laser fluence regime, the energy efficiency of mass ablation is higher for femtosecond pulses than for nanosecond pulses, but the ion production efficiency is lower. (C) 2013 American Institute of Physics. [http://dx.doi.org/10.1063/1.4792033]
\end{abstract}

\section{INTRODUCTION}

The dynamics of ablation plume expansion in femtosecond (fs) laser ablation of solid materials is of interest in micromachining, thin film deposition and microanalysis. ${ }^{1-9}$ It is now well established that $f_{s}$ laser ablation of solids is significantly different from nanosecond (ns) ablation. In $f_{S}$ ablation the time available for heat conduction is of the order of the electron-lattice relaxation time, typically $1-10 \mathrm{ps}$. The hydrodynamic motion of the ablated material commences on the same time scale, thus for sub-ps laser pulses there is no interaction of the laser with ablated material. The plume is typically characterized by the kinetic energy and angular distribution of the ablated particles, ${ }^{2,6-13}$ which in turn are determined by the dimensions of the ablation spot and the thickness of the layer of ablated material when the adiabatic expansion of the ablation plume commences.

Most of the comparisons between $n s$ and $f s$ experiments or film depositions have been carried out for the light elements, ${ }^{2,3,7,12,14}$ in particular carbon, which may not be representative for a broader set of elements. Another significant feature is that most of the experiments on medium, or heavy elements, have been carried with laser wavelengths in the near infrared around $800 \mathrm{~nm}^{2,6,7}$ or in the visible at $527 \mathrm{~nm}$, or $620 \mathrm{~nm},{ }^{3,8-10,13}$ whereas $n s$ ablation is typically studied for UV lasers at $355 \mathrm{~nm}$ or $248 \mathrm{~nm}$. However, one should note that the strong-field excitation induced by $f s$-lasers makes it possible to ablate materials using longer wavelengths where the materials are transparent to the laser light. ${ }^{15}$

Plume studies of $f_{s}$ laser ablation are often based on timeand space-resolved spectroscopy from which it can be difficult to extract the velocity and angular distributions of the ablated particles. Spectroscopic measurements of emission from excited atomic and ionic species may not give a representative picture of all the ablated material. In particular, it is known that in $f s$ irradiation a significant part of the ablation occurs

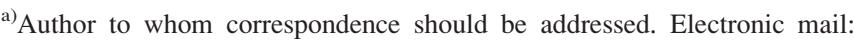
josc@fotonik.dtu.dk.
}

via emission of nanoparticles (NPs), which leave the target at lower velocity than atoms or ions and emit a continuous light spectrum. ${ }^{15-17}$ There are some reports of ion energy distribution measurements using Langmuir probes ${ }^{7}$ or ion energy analyzers, ${ }^{2,4,7,11}$ but these measurements have been made in a direction close to the normal of the target surface, and do not give information about the shape of the ablation plume. Donnelly et $a l^{8,9}$ have used ion probes to measure the plume shape and the ion energy distribution in $f s$ ablation of nickel.

In this paper, we describe the results of an experiment to measure the energy and angular distributions of the plasma produced by ablation of a silver $(\mathrm{Ag})$ target with a $f s \mathrm{UV}$ laser. The angular distribution of the net deposition was also measured. The results were compared with similar measurements for $n s$ pulses. We show that the adiabatic and isentropic plume expansion model ${ }^{18,19}$ provides a good description of the plume expansion in $f s$ ablation. This model was developed for the expansion of the neutral vapour produced by pulsed laser ablation, but has been found to provide a good description of the expansion of ionized $n s$ laser ablation plumes. ${ }^{20-22}$ The parameters of the model are realistic, and the flip-over effect, whereby for an elliptical ablation spot the major axis of the expanding plume becomes orthogonal to the major axis of the ablation spot, was observed. The main result of the present work is that both plasma plume shape and the angular distribution of deposition are significantly narrower for $f s$ ablation than for the corresponding case of $n s$ ablation. However the plasma and deposition plumes are of finite angular width, and clearly do not correspond to unidirectional flow along the target normal, as is described in Ref. 23. In the present experiment the laser beam strikes the target at normal incidence, though the laser spot is rectangular. However the conclusions drawn here are generally applicable, in particular to pulsed laser deposition (PLD) where non-normal incidence is used.

\section{EXPERIMENT}

The $f s$ ablation measurements were performed at the UV laser facility at IESL-FORTH, Crete, using a $500 \mathrm{fs}$, 
$248 \mathrm{~nm}$ laser. Laser pulses at $496 \mathrm{~nm}$ were generated in a distributed feedback dye laser before frequency doubling and amplification in a $\mathrm{KrF}$ excimer laser amplifier. ${ }^{24}$ The laser beam was delivered, using a demagnifying optical system, as a rectangular spot $0.62 \mathrm{~mm} \times 0.26 \mathrm{~mm}\left(0.0016 \mathrm{~cm}^{2}\right.$ area $)$ at normal incidence onto a $\mathrm{Ag}$ target in a vacuum chamber with a base pressure of $10^{-7}$ mbar. The laser beam could be adjusted to orient the long axis of the spot either horizontal or vertical, and the target could be rotated to a new ablation spot after each sequence of shots. To identify the ablation regime of this experiment the ablation depth per pulse was measured as function of laser fluence by keeping the target fixed and delivering between 500 and 1000 laser pulses. The ablation crater profile was measured across the long and short dimensions using a Dektak surface profilometer. An array of 13 planar Langmuir probes was arranged in the horizontal plane in a semi-circular arc around the laser ablation spot at a distance of $80 \mathrm{~mm}$, as shown in Fig. 1. The planar probes were biased negatively at $-10 \mathrm{~V}$ to reject plasma electrons and to measure the time-of-flight (TOF) ion current signal due to the plasma flow. The planar probes were similar to those in Ref. 25 and had an area of $0.04 \mathrm{~cm}^{2}$. The collecting surface was oriented to face the ablation spot, and thus the plasma flow. While recording the signal from a particular probe, all other probes were grounded. An identical system with cylindrical probes has been used for ion probe measurements with $n s$ pulses. ${ }^{21}$ A simple homemade lowresolution cylindrical ion energy analyzer with a Faraday plate detector was used to identify the main ionic species in the ablation plasma. The deposition was measured by placing a semi-circular stripe of transparent plastic around the ablation spot at the same radius as the probes. After an appropriate number of laser pulses the thickness of the Ag film was determined by measuring the optical transmission with a He$\mathrm{Ne}$ laser $^{26}$ and using the known optical properties of $\mathrm{Ag}$ metal. $^{27}$

\section{RESULTS AND DISCUSSION}

Figure 2 shows the fluence variation of the measured $\mathrm{fs}$ ablation depth per pulse in the fluence range 0.3 to $2 \mathrm{~J} \mathrm{~cm}^{-2}$.

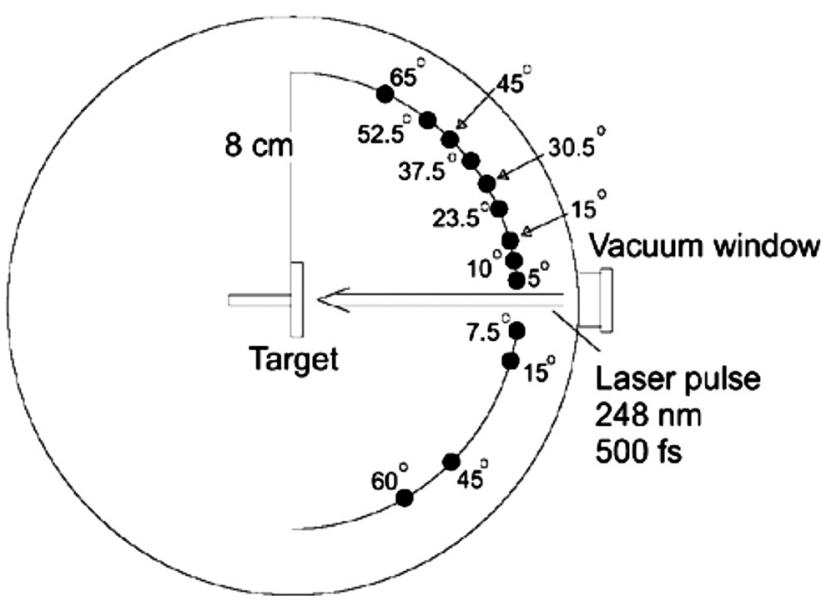

FIG. 1. Geometry of the setup used for the ion probe measurements in UV fs laser ablation experiment at IESL-FORTH, Crete. Only planar probes (indicated with dots) were used.
At low fluence there is a logarithmic dependence consistent with the analysis of Nolte et al. ${ }^{5}$ In this regime the ablation is determined by the penetration of light into the solid, $\alpha^{-1} \sim 20 \mathrm{~nm}$. For larger fluence the depth increases linearly with fluence, which reflects the increasing importance of heat conduction. $^{28,29}$ The ablation depth at $2 \mathrm{~J} \mathrm{~cm}^{-2}$ is $\sim 160 \mathrm{~nm}$. Vestentoft and Balling measured a value of $\sim 100 \mathrm{~nm}$ at $2 \mathrm{~J} \mathrm{~cm}^{-2}$ for ablation with $100 \mathrm{fs} 800 \mathrm{~nm}$ pulses; ${ }^{28}$ the higher value measured here is most likely due to the lower target reflectivity for UV irradiation. In both cases the laser pulses are much shorter than the electron-lattice relaxation time, which is $\sim 9.4 \mathrm{ps}$ for $\mathrm{Ag}$ in the ablation conditions considered here. ${ }^{30}$ It should be noted that after the delivery of 500-1000 pulses at the same position the floor of the ablation crater is highly structured, showing $50 \%$ modulation of the ablation depth on a typical lateral scale length of $50 \mu \mathrm{m}$.

In making the ion probe measurements it was noted that the first shot on a particular target location gave rise to a signal of higher amplitude and shorter TOF than for subsequent shots delivered in quick succession. Figure 3(a) shows the ion signals obtained for the first, second, and third shots delivered at a repetition rate of $1 \mathrm{~Hz}$. Subsequent shots are similar to the third shot. It was also noted that if the irradiation is stopped for a few seconds the fast ion peak reappears when the irradiation is restarted. These observations indicate the buildup of low-Z contamination of the Ag surface. This was confirmed using the cylindrical ion energy analyser. Fig. 3(b) shows TOF signals of the ions transmitted through the analyser when the pass energy was set at $47 \mathrm{eV}$ for singly-charged ions. The approximate ion mass was determined from the TOF. When the target is rotating we observe ion signals due to singly-ionised $\mathrm{H}, \mathrm{C}$, and/or $\mathrm{O}$ and $\mathrm{Ag}$, as there is sufficient time between laser shots on the same location on the target for the buildup of surface contamination. A similar low-Z impurity peak was observed in $f s$ ablation of $\mathrm{Ni}^{8}{ }^{8}$ However, with the target stationary only the Ag ion signal is observed. The ion probe signals reported below were obtained after laser ablative cleaning of the target.

Figure 4(a) shows the fluence variation of the ion signals measured near the target normal. The fluence was varied by changing the laser pulse energy while keeping the beam spot size constant. To minimise the problem of surface contamination, each TOF-spectrum is an average of the last 5 laser shots in a series of 10 shots fired at a repetition rate of $2 \mathrm{~Hz}$.

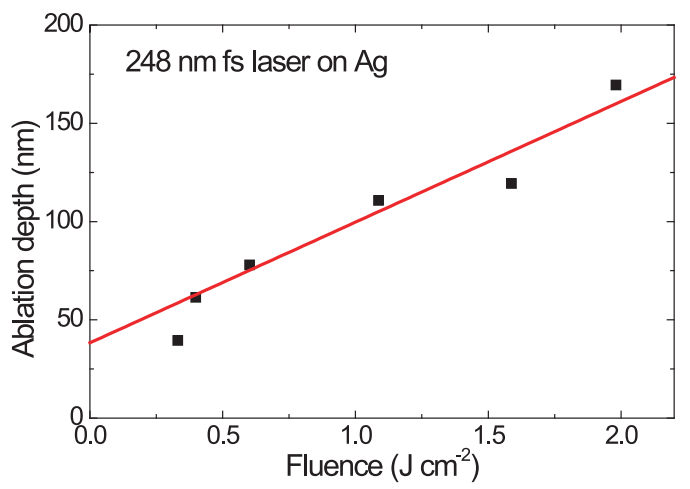

FIG. 2. The ablation depth as a function of laser fluence with vertical beam spot. 

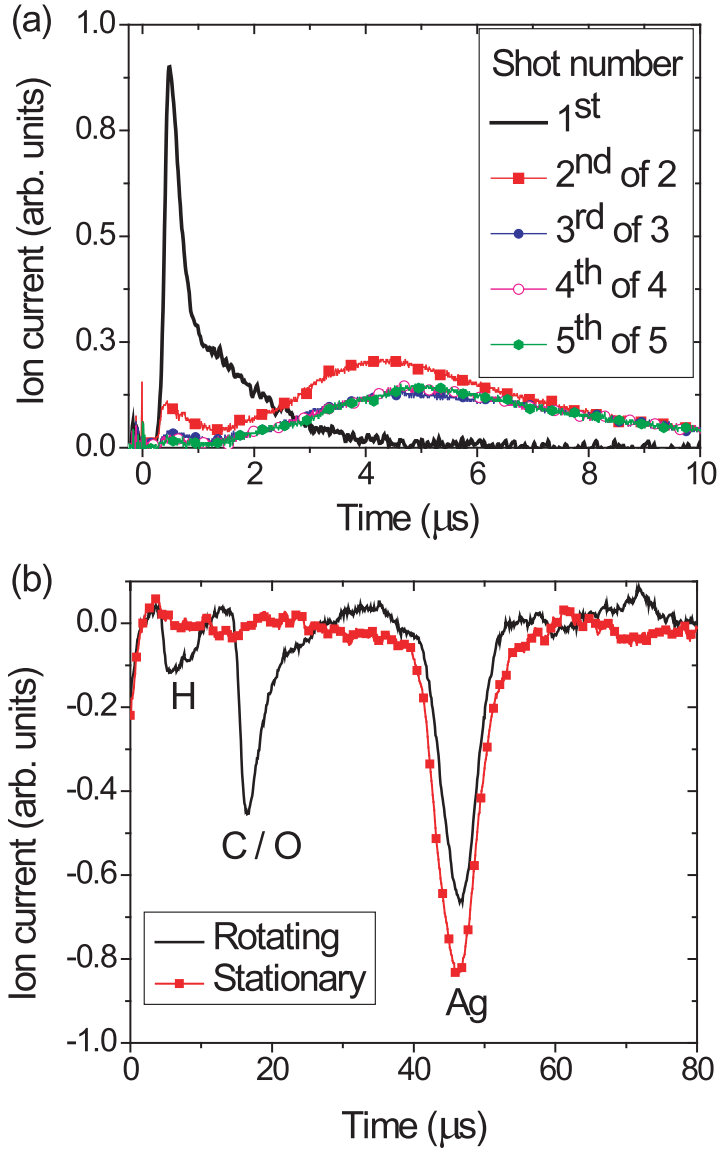

FIG. 3. (a) Ion signals on the probe at $7.5^{\circ}$ from target normal for laser pulses delivered at $2 \mathrm{~Hz}$ on 5 different beam spots. (b) Ion energy analyser signals at an angle of $45^{\circ}$ from the normal for a $\mathrm{Ag}$ target, both rotating and stationary, obtained with the ion pass energy set at $47 \mathrm{eV}$. The fluence was $2.2 \mathrm{~J} \mathrm{~cm}^{-2}$ with the laser at normal incidence.

As the fluence is increased the amplitude of the signal increases, and the TOF corresponding to maximum ion flux decreases, but the characteristic shape of the signal remains the same. Figure 4(b) shows that the integrated ion charge collected by the probe increases linearly with fluence. This figure also shows that ion energy corresponding to the TOF at maximum ion flux increases monotonically from $\sim 40 \mathrm{eV}$ at the ablation threshold to $\mathrm{a} \sim 150 \mathrm{eV}$ at $2 \mathrm{~J} \mathrm{~cm}^{-2}$. A similar increase of the ion energy, in nearly the same fluence range, was seen for $n s$ ablation of $\mathrm{Ag}$ at $355 \mathrm{~nm} .^{31}$

Figure 5(a) shows TOF spectra at different angles measured from the target normal for $f s$ ablation at $2.4 \mathrm{~J} \mathrm{~cm}^{-2}$. The signal amplitude is greatest and the TOF is least along the target normal. There is no indication of a bimodal velocity distribution reported in Refs. 2 and 7. The very weak feature near $1 \mu \mathrm{s}$ is due to some residual low-Z contamination. The general behavior of these ion signals is quite similar to that obtained for $n s$ ablation of Ag, which is shown in Fig. 5(b) for comparison. ${ }^{32,33}$ The $n s$ ablation was done using a $248 \mathrm{~nm}, 26 \mathrm{~ns}$ excimer laser with $2.0 \mathrm{~J} \mathrm{~cm}^{-2}$ on a $1.8 \mathrm{~mm}$ $\times 0.7 \mathrm{~mm}$ spot $\left(0.013 \mathrm{~cm}^{2}\right.$ area $)$ and a $3 \mathrm{~mm} \times 1.5 \mathrm{~mm}$ planar probe was positioned at $41 \mathrm{~mm}$. This ablation spot is $\sim 3$ times larger than the $f s$ laser spot, though, as will be discussed below, the angular size of the ion fluence and deposition plumes are wider than the $f s$ case. The ion energy
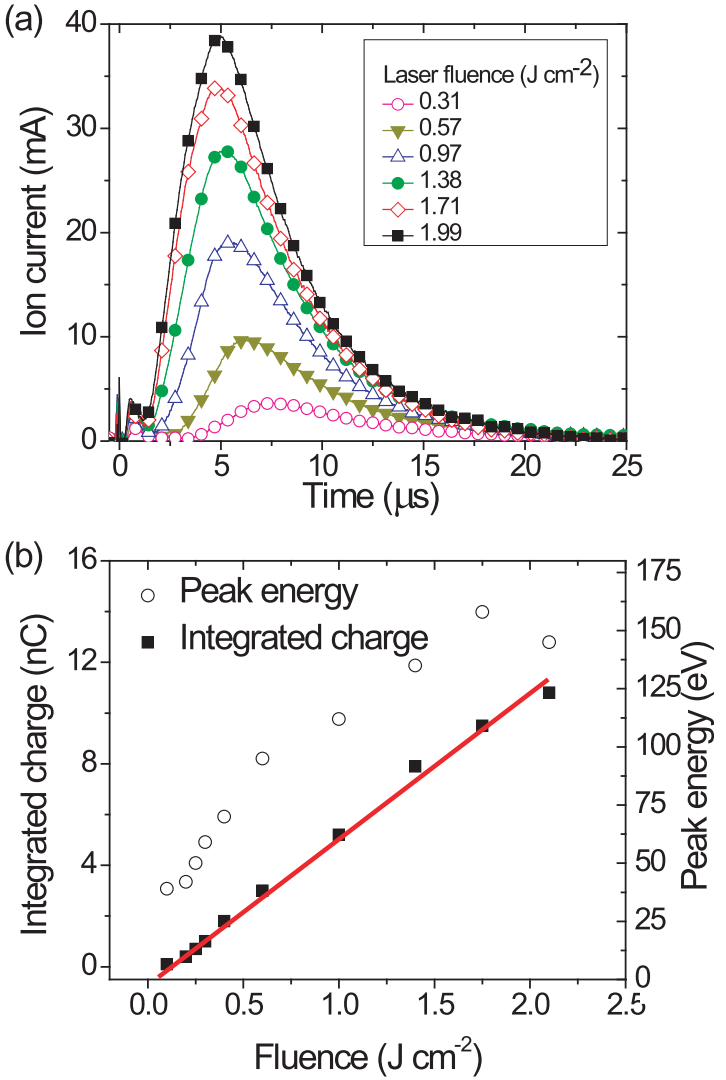

FIG. 4. (a) TOF ion signals from a planar probe at $23.5^{\circ}$ from the target normal for different values of fluence using the $f s$-laser with vertical orientation of the beam spot. (b) Fluence variation of the integrated charge and ion energy at peak ion flux for the signals in Fig. 4(a)

corresponding to the TOF for peak ion flux is $160 \mathrm{eV}$, which is quite similar to the value for $f_{s}$ ablation at the same fluence.

The angular distribution of ion TOF spectra was measured for two orientations of the beam spot; with the long axis $(x$-axis) both horizontal and vertical, and the results are shown in Fig. 6. With the long axis vertical the smaller horizontal spot dimension gives rise to wider angular distribution in the horizontal plane and vice versa. This so-called "flipover effect" is in agreement with the gas dynamics model of plume expansion. ${ }^{18,19}$ The time-integrated ion signals were fitted with the angular distribution $F(\varphi)$ derived from the gas dynamical expansion model

$$
F(\varphi) / F(0)=\left(1+\tan ^{2} \varphi\right)^{3 / 2}\left[1+k^{2} \tan ^{2} \varphi\right]^{-3 / 2},
$$

where the fitting parameter $k$ is the asymptotic value of the longitudinal-to-transverse axes ratio of the semi-ellipsoidal shaped ablation plume. The parameter $k$ is a measure of the elongation of the plume, i.e., a larger $k$ means a more forward-peaked plume. This distribution describes the particle deposition on a hemispherical surface, in contrast to the formula in Ref. 18 which describes particle deposition on a planar substrate positioned parallel to the target surface. The fits in Fig. 6 show that when the long axis of the beam spot is horizontal the ion angular distribution in the horizontal plane is described by $k_{x}=6.2$ and by $k_{y}=4.0$ with the long axis of the beam spot in the vertical plane. 

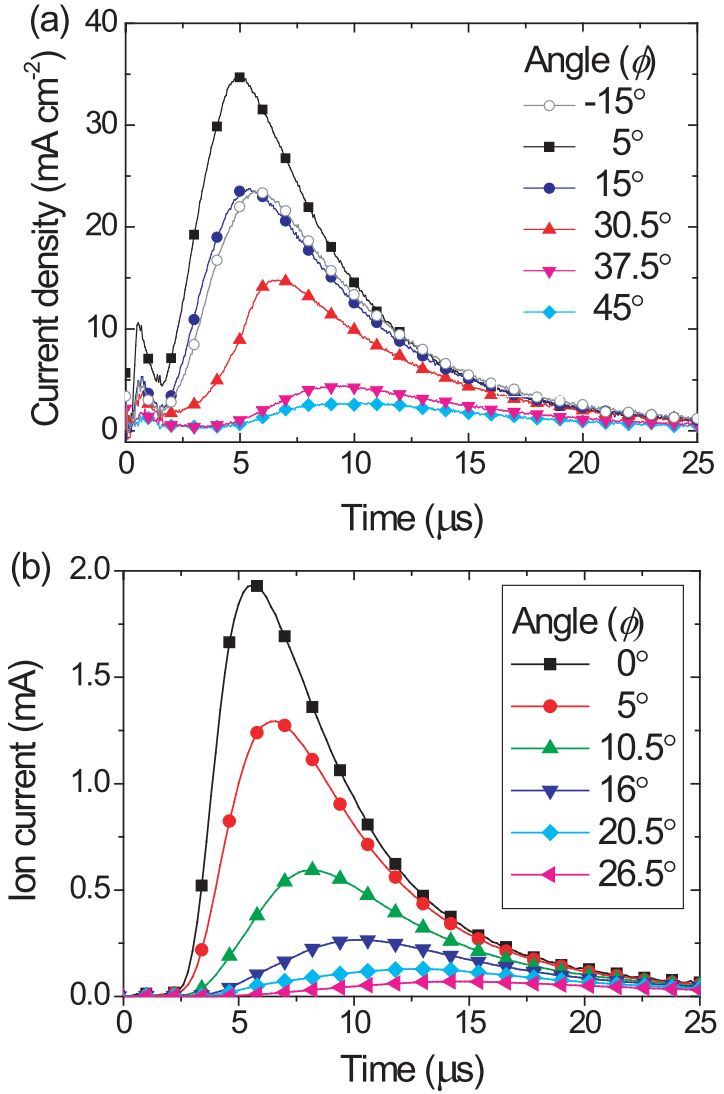

FIG. 5. Angular variation of TOF ion signals for (a) $f s$ ablation of silver $2.2 \mathrm{~J} \mathrm{~cm}^{-2}$ with vertical beam spot, and (b) $n s$ laser ablation at $248 \mathrm{~nm}$, $2.0 \mathrm{~J} \mathrm{~cm}^{-2}$ on a $1.8 \mathrm{~mm} \times 0.7 \mathrm{~mm}$ spot and $45^{\circ}$ angle of incidence. The signals were recorded by rotating a planar probe at $41 \mathrm{~mm}$ from the target. ${ }^{32,33}$

The flip-over effect occurs whenever the laser spot is not rotationally symmetric. ${ }^{18,22}$ The plume expansion, which is assumed to be adiabatic and isentropic, is driven by the pressure gradients in the ablated material at the time when the adiabatic expansion commences. Typically at this time the ablated material exists as a thin layer of thickness $\mathrm{Z}_{0}$ on the ablation spot. Thus the pressure gradient and the plume acceleration are largest normal to the target surface and a forward-peaked ellipsoid plume is produced. Similarly, when the ablation spot is not rotationally symmetric the transverse pressure gradient is higher in the direction of the smaller spot dimension. For a rectangular laser beam spot the plume will exhibit a flip-over, i.e., during the expansion the plume evolves in such a way that that the major axis lies at $90^{\circ}$ to that of the initial spot.

The angular distribution of deposition (ions, neutral, and nanoparticles) was measured by depositing a Ag film on the inner side of a semi-cylindrical plastic sheet mounted at the same radial location as the probes. Figure 7(a) shows a photograph of a Ag film deposited using 16000 laser shots with the long axis ( $x$-axis) of the beam vertical; a new ablation spot was selected after every 200 laser shots. For this measurement the probe setup together with the target were rotated in the horizontal plane such that the laser struck the silver target at an angle of $10^{\circ}$. The spatial variation of the film thickness was determined by light transmission, as described above. Then knowing the radius of curvature of
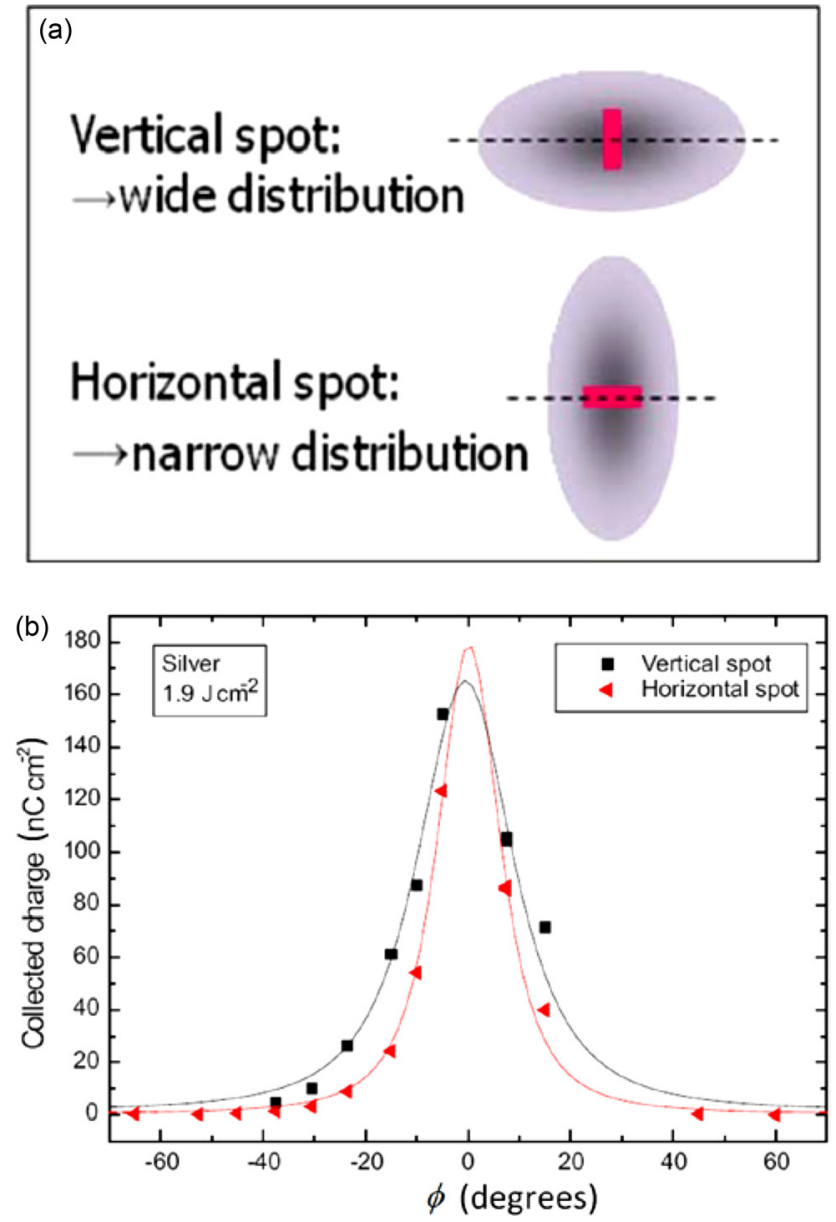

FIG. 6. (a) Schematic showing the beam spot (pink rectangle) orientation and plume deposition (grey ellipse). (b) Angular variation of the ion fluence in the horizontal plane for $f s$ ablation of $\mathrm{Ag}$ for both vertical and horizontal orientations of the beam spot.

the plastic sheet, the angular distribution of the film thickness was found, and this is shown in Fig. 7(b). Fitting the distribution to Eq. (1) yields $k_{y}=2.4$. This can be compared with $k_{y}=4.0$ for the ion distribution. Thus, the plasma part of the plume is significantly narrower in angle than the overall plume giving rise to deposition. The opposite tendency has been observed in $f s$ ablation of nickel for fluence values below $0.8 \mathrm{~J} \mathrm{~cm}{ }^{2} .{ }^{34}$ The reason for this difference in behaviour is not clear at this stage, but may be related to the higher fluence used here combined with the low reflectivity for silver at $248 \mathrm{~nm}$. In any case the deposition measurement shows no indication of the presence of a very narrowlycollimated ablation jet near the target normal, as was reported in Ref. 23. Figure 8 shows the angular variation of the ion fluence and deposition on a $41 \mathrm{~mm}$ radius cylindrical surface centered on the ablation spot for $n s$ ablation under the same conditions as for the data in Fig. 5(b). As for the plume shape in $f_{S}$ ablation (Fig. 7), the plasma part of the plume is more forward-peaked than the net deposition.

It is of interest to make a quantitative comparison of the ablation yield, total deposition and total ion yield. For $f s$ ablation at $2.4 \mathrm{~J} \mathrm{~cm}^{-2}$ the average ablation depth is $185 \mathrm{~nm}$ (slightly outside range of Fig. 2) and the number of ablated atoms calculated from the crater dimensions is $1.7 \times 10^{15}$. 

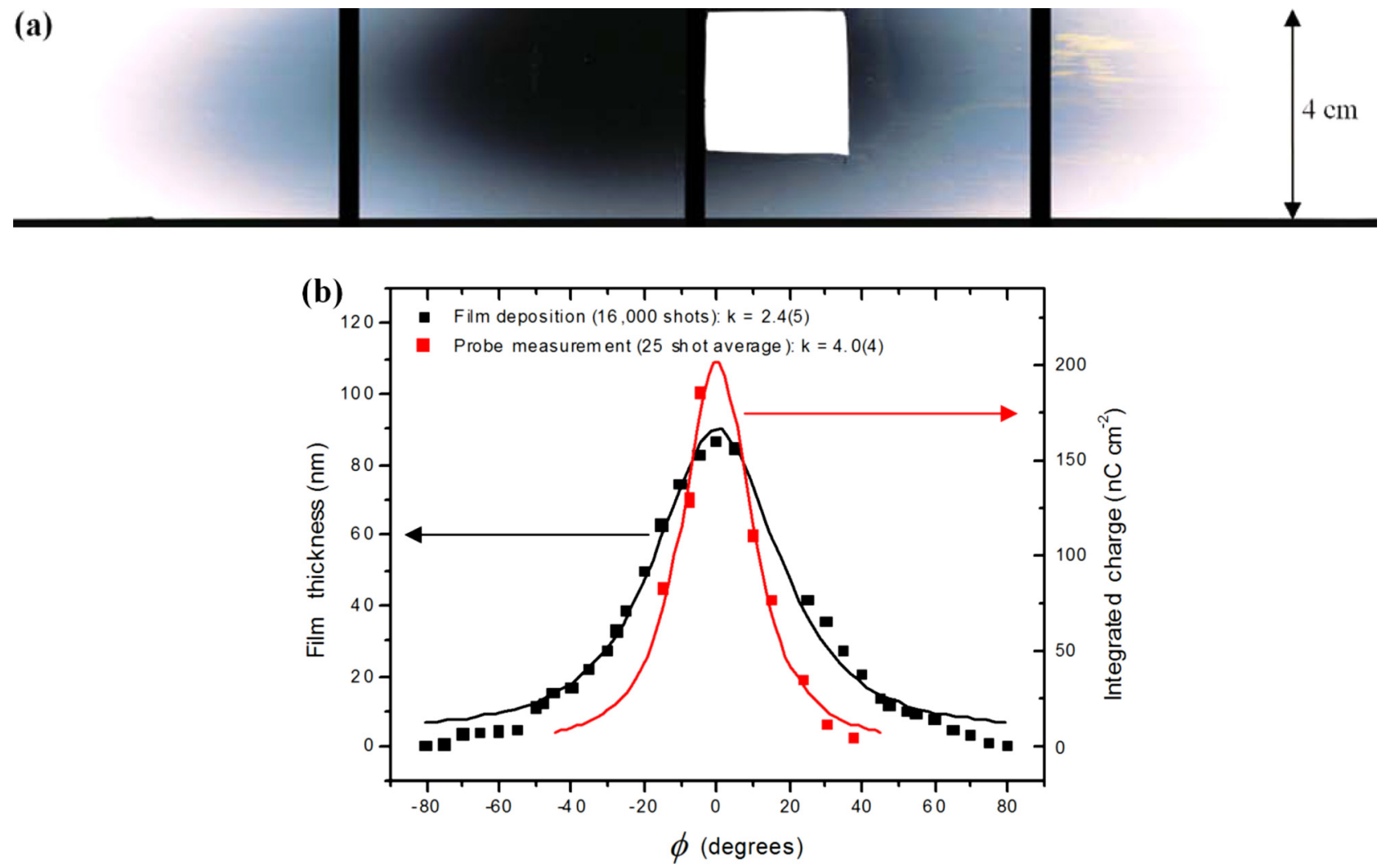

FIG. 7. (a) Photograph of the Ag film deposited on a semi-cylindrical plastic film centered of the ablation spot using $f s$ ablation. (b) Angular variation of the deposition thickness and the ion fluence for $f s$ ablation of $\mathrm{Ag}$ using a vertical beam spot and $10^{\circ}$ angle of incidence.

For a semi-ellipsoidal plume deposited on a substrate at a distance of $d$ from the ablation spot, the total deposited yield $Y$ is related to the deposition per unit area $F(0)$ in the direction of the target normal direction and the $k$-values, $k_{x}$ and $k_{y}$ of the deposition plume by ${ }^{22}$

$$
Y=2 \pi d^{2} F(0) / k_{x} k_{y} .
$$

Since $d=80 \mathrm{~mm}, F(0)=3.3 \times 10^{13}$ atoms $\mathrm{cm}^{-2}$ pulse $^{-1}$, $k_{x}=3.8$ (estimated as described below) and $k_{y}=2.4$ the total number of atoms deposited per pulse is $Y=1.5 \times 10^{15}$, which is of the same order as the number of ablated atoms as measured from the ablation crater. Repeating this calculation for

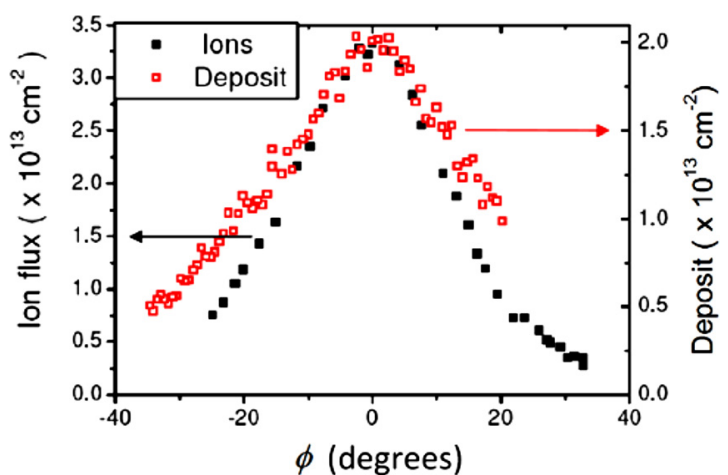

FIG. 8. Angular variation of ion fluence and net deposition per pulse for $n s$ ablation of $\mathrm{Ag}$ at $248 \mathrm{~nm}$ and $2.0 \mathrm{~J} \mathrm{~cm}-2$ on a $0.013 \mathrm{~cm}^{2}$ beam spot. The probe distance was $41 \mathrm{~mm}$. The fitting curves (not shown here) with Eq. (1) gave $k_{x}=2.9$ for the ion distribution and $k_{x}=1.9$ for the deposit. ${ }^{32,33}$ the ions gives a total ion yield of $2.0 \times 10^{13}$, which is only about $1 \%$ of the ablated atoms. Noting that the ion fluence is a small fraction of the net deposition, it can be concluded that sputtering by ions is not a significant process.

It is also of interest to compare the efficiencies of $n s$ and $f s$ ablation with respect to both material removal and ion production. For the $f s$ ablation described above, the ablation efficiency is $4.5 \times 10^{14}$ atoms/mJ of incident laser energy, which corresponds to $\sim 14 \mathrm{eV}$ per atom, while the ion production efficiency is $5 \times 10^{12}$ ions/mJ. Referring to the data in Refs. 32 and 33 for ablation of Ag with $26 \mathrm{~ns}, 248 \mathrm{~nm}$ laser irradiation at $2 \mathrm{~J} \mathrm{~cm}^{-2}$ on a $0.013 \mathrm{~cm}^{2}$ spot, it can be seen that the ablation efficiency is $4.2 \times 10^{13}$ atoms $/ \mathrm{mJ}$ and the ion production efficiency is $2.5 \times 10^{13}$ ions $/ \mathrm{mJ}$. Thus it is clear, that for the laser fluence range considered here, the ablation efficiency is $\sim 10$ times higher for $f s$ irradiation, while the ion production efficiency is $\sim 5$ times lower. Since $f s$ and $n s$ laser ablation proceed in very different ways, it is not possible to identify a single factor to account for the very different ablation efficiencies. However, it can be noted that since the ns pulse is much longer than the electron-phonon relaxation time, which determines the time for heat conduction in the $f s$ case, the heat diffusion depth is smaller in the $f s$ case. In $f s$ ablation most of the ablated material is removed by nanofragmentation of superheated material, ${ }^{15,17,34,35}$ while in the $n s$ ablation material removal is limited by surface evaporation from the laser heated surface. In $n s$ ablation plume material evolved during the laser pulse absorbs the laser light leading to a reduction of the energy coupled to the target. It can also be noted that the efficiency of $f s$ ablation 
TABLE I. Comparison of k-values for femtosecond and nanosecond ablation.

\begin{tabular}{lcc}
\hline \hline Laser pulse Ablation spot dimensions & Ion $k$-values Initial thickness & Deposition $k$-values \\
\hline $500 \mathrm{fs}$ & $k_{x}=6.2, k_{y}=4.0$ & $k_{x}=3.8,{ }^{\mathrm{a}} k_{y}=4.0$ \\
$0.62 \mathrm{~mm} \times 0.26 \mathrm{~mm}$ & $\mathrm{Z}_{0}=0.18 \mu \mathrm{m}$ & $\mathrm{Z}_{0}=5 \mu \mathrm{m}$ \\
$26 \mathrm{~ns}$ & $k_{x}=2.9, k_{y}=1.9$ & $k_{x}=1.9, k_{y}=1.2$ \\
$1.8 \mathrm{~mm} \times 0.7 \mathrm{~mm}$ & $\mathrm{Z}_{0}=29 \mu \mathrm{m}$ & $\mathrm{Z}_{0}=160 \mu \mathrm{m}$ \\
$26 \mathrm{~ns}$ & $k_{x}=2.2, k_{y}=1.5$ & $k_{x} \sim 1.2, k_{y} \sim 1.0$ \\
$0.62 \mathrm{~mm} \times 0.26 \mathrm{~mm}$ & $\mathrm{Z}_{0}=29 \mu \mathrm{m}$ & $\mathrm{Z}_{0}=160 \mu \mathrm{m}$ \\
\hline \hline
\end{tabular}

${ }^{\mathrm{a}}$ Estimated using Anisimov model.

${ }^{\mathrm{b}}$ Estimated $k$-values found from the Anisimov model using the $f s$ spot dimensions but the initial ablated layer thickness corresponding to $n s$ ablation.

of $\mathrm{Ni}$ is one order of magnitude larger than $n s$ ablation at approximately the same wavelength. ${ }^{9,36}$ While the ablation efficiency is higher with $f s$ lasers, it should be noted that these lasers are more complicated and expensive than the $n s$ lasers normally used for ablation.

There are reports of the observation of extremely narrow plumes for $f s$ ablation, ${ }^{23}$ but as mentioned above, this has not been observed in the present experiment. Spectroscopic measurements of visible emission from ablation of $\mathrm{ZnO}^{3}$ $\mathrm{Ti}^{12}$ and $\mathrm{BaTiO}_{3}$ (Ref. 37) clearly show that the plume of excited species is narrower for $f_{s}$ ablation than $n s$ ablation. This general trend is supported by the ion and deposition data presented here. The comparison of plume shapes for different ablation regimes is most easily done by comparing the $k$-values. The $k$-values for both the ion and deposition plumes for $f s$ and $n s$ ablation are compared in Table I. The $n s$ ablation was done with a larger laser spot, but we can use the Anisimov model ${ }^{18,19}$ to make an estimate of the $k$-values for similar ablation conditions on a smaller spot. Running the Anisimov model, with the adiabatic index $\gamma=1.25$ (Ref. 21 ) for the $n s$ ablation spot with a range of values for $Z_{0}$ and comparing the predicted $k$-values with the measured values allows us to find the value of $\mathrm{Z}_{0}$ for $n s$ ablation; the values obtained are $29 \mu \mathrm{m}$ for the ion plume and $160 \mu \mathrm{m}$ for the deposition plume. Then using these values of $Z_{0}$ and the $f_{s}$ spot dimensions, the Anisimov model gives $k_{x}=2.2$ and $k_{y}=1.5$ for the ions and $k_{x} \sim 1.2$ and $k_{y} \sim 1.0$ for the deposition, as shown in Table I. A value of $k_{y} \sim 1.0$ implies that the plume shape is approximately hemispherically symmetric in the yz-plane. Thus it is clear that, for the same ablation spot dimensions, $f s$ ablation gives rise to much narrower ion and deposition plumes than $n s$ ablation. Unfortunately these $k$ values could not be confirmed by experiment since when the $f s$ beam was apertured to yield a circular beam the laser energy was reduced and signal on most of the probes was too small for measurement. It is possible to run the UV laser facility at IESL-FORTH in $n s$ mode with same beam shape as the $f s$ mode, but again the ion signals were insufficient for reliable measurement. The same trend towards narrower ablation plumes in $f s$ ablation is observed in ablation of $\mathrm{Ni}$ using $250 f s$ laser pulses at $527 \mathrm{~nm} .{ }^{9}$ The asymptotic aspect ratio of the ablation plume depends on the ratio of thickness to lateral dimension of the ablated material at the time when the adiabatic expansion commences. Thus, the results presented here and in Ref. 9 indicate that the initial thicknesses of both the atomic and NP ablation layers in $f s$ ablation are much less than for $n s$ ablation.
We need to consider if laser energy arriving before the main $f s$ pulse has any influence on our measurements. The present measurements have been performed relatively close to the ablation threshold. ${ }^{5}$ The energy of any prepulse on a $n s$ timescale has been estimated by Geretovszky et al. ${ }^{38}$ to be at most $25 \%$ of the total pulse energy and the contribution will not be significant, as can be seen from Fig. 2 .

A possible complicating feature is the roughness of the target surface, which is already induced by the first laser shot. Clearly it would be desirable to obtain the ion angular distribution data from the first shot of a virgin surface. However, this is not possible because of the low- $\mathrm{Z}$ contamination of the target, and cleaning by even a few shots leads to roughening of the surface. The Anisimov model ${ }^{18,19}$ of plume expansion shows that there is negligible lateral expansion of the plume until the plume extent in the forward direction is comparable to the lateral radius, which in our case will take $\sim 50 \mathrm{~ns}$. This time is sufficiently long for ion-ion collisions to randomise any directed plasma motion arising from non-planarity of the crater floor.

\section{CONCLUSION}

In summary, we have studied the plume dynamics from $500 \mathrm{fs}$ laser ablation of silver at $248 \mathrm{~nm}$ with Langmuir probe and thin film deposition techniques. The TOF spectra from $f s$ laser ablation show a single peak and are quite similar to those for $n s$ ablation at $248 \mathrm{~nm}$ and $355 \mathrm{~nm}$ at the same value of fluence. ${ }^{21,32,33}$ The angular distribution of ions, as well as that of the deposition, can be analyzed and quantified in terms of Anisimov's plume expansion model with realistic parameters. The present data for the plume dynamics indicate that the expansion is determined by the initial stage of the plume formation rather than by direct interaction between the ablated particles and the laser. An additional support for the validity of Anisimov's model for $f_{s}$ ablation is the observation of a distinct flip-over effect for a horizontal and vertical laser beam spot. The angular distribution of ions and of the total deposit is somewhat narrower than for $n s$ pulses evaluated on the basis of Anisimov's model. The energy efficiency of $f s$ laser ablation is $\sim 10$ higher than $n s$ ablation, while the ion production efficiency is lower for $f s$ ablation.

\section{ACKNOWLEDGMENTS}

The authors want to thank Arne Nordskov for excellent technical assistance and the staff at IESL-FORTH for most 
helpful local support. This work was supported by a grant from the EU Growth Programme. The work was carried out, in part, at the Ultraviolet Laser Facility operating at FORTH (Heraklion, Crete, Greece) with support from the EC through the Human Potential-Access to Research Infrastructures program (Contract No. HPRI-CT-2001-00139).

${ }^{1}$ J. Krüger and W. Kautek, Laser Phys. 9, 30 (1999).

${ }^{2}$ S. Amoruso, X. Wang, C. Altucci, C. De Lisio, M. Armenante, R. Bruzzese, and R. Velotta, Appl. Phys. Lett. 77, 3728 (2000).

${ }^{3}$ J. Perrière, E. Millon, W. Seiler, C. Boulmer-Leborgne, V. Cracuin, O. Albert, J. C. Loulergue, and J. Etchepare, J. Appl. Phys. 91, 690 (2002).

${ }^{4}$ R. Stoian, A. Rosenfeld, D. Ashkenasi, I. V. Hertel, N. M. Bulgakova, and E. E. B. Campbell, Phys. Rev. Lett. 88, 097603 (2002).

${ }^{5}$ S. Nolte, C. Momma, H. Jacobs, A. Tünnermann, B. N. Chichkov, B. Wellegehausen, and H. Welling, J. Opt. Soc. Am. B 14, 2716 (1997).

${ }^{6}$ P. P. Pronko, Z. Zhang, and P. A. VanRompay, Appl Surf. Sci. 208-209, 492 (2003).

${ }^{7}$ Z. Zhang, P. A. VanRompay, J. A. Nees, and P. P. Pronko, J. Appl. Phys. 92, 2867 (2002).

${ }^{8}$ T. Donnelly, J. G. Lunney, S. Amoruso, R., Bruzzese, X. Wang, and X. Ni, J. Appl. Phys. 108, 043309 (2010).

${ }^{9}$ T. Donnelly, J. G. Lunney, S. Amoruso, R., Bruzzese, X. Wang, and X. Ni, Appl. Phys. A 100, 569 (2010).

${ }^{10}$ M. Sanz, M. Castillejo, S. Amoruso, G. Ausanio, R. Bruzzese, and X. Wang, Appl. Phys. A 101, 639 (2010).

${ }^{11}$ V. Schmidt, W. Husinsky, and G. Betz, Phys. Rev. Lett. 85, 3516 (2000).

${ }^{12}$ O. Albert, Y. Glinec, J. C. Loulergue, J. Etchepare, C. Boulmer-Leborgne, J. Perriére, and E. Millon, Appl. Phys. A 76, 319 (2003).

${ }^{13}$ A.-S. Loir, F. Garrelie, J.-L. Subtil, F. Goutaland, M. Belin, R. Le Harzic, C. Donnet, Y. Ouerdane, F. Rogemond, and P. Laporte, Appl. Surf. Sci. 208-209, 553 (2003).

${ }^{14}$ F. Claeyssens, M. N. R. Ahsfold, E. Sofoulakis, C. G. Ristoscu, D. Anglos, and C. Fotakis, J. Appl. Phys. 91, 6162 (2002).

${ }^{15}$ P. Balling and J. Schou, Rep. Prog. Phys. 76, 036502 (2013).
${ }^{16}$ S. Amoruso, R. Bruzzese, N. Spinelli, R. Velotta, M. Vitiello, X. Wang, G. Ausanio, V. Iannotti, and L. Lanotte, Appl. Lett. 84, 4502 (2004).

${ }^{17}$ M. Sanz, R. de Nalda, J. F. Marco, J. G. Izquierdo, L. Banares, and M. Castillejo, J. Phys. Chem. C 114, 4864 (2010).

${ }^{18}$ S. I. Anisimov, B. S. Luk'yanchuk, and A. Luches, Appl. Surf. Sci. 96-98, 24 (1996).

${ }^{19}$ S. I. Anisimov, D. Bäuerle, and B. S. Luk'yanchuk, Phys. Rev. B 48, 12076 (1993).

${ }^{20}$ J. Schou. S. Amoruso, and J. G. Lunney, in Laser Ablation and Its Applications, edited by C. L. Phipps (Springer, 2007), pp. 67-95.

${ }^{21}$ B. Thestrup, B. Toftmann, J. Schou, B. Doggett, and J. G. Lunney, Appl. Surf. Sci. 197-198, 175 (2002).

${ }^{22}$ B. Toftmann, J. Schou, and J. G. Lunney, Phys. Rev. B 67, 104101 (2003).

${ }^{23}$ A. M. Komashko, M. D. Feit, and A. M. Rubenchik, Proc. SPIE 3935, 97 (2000).

${ }^{24}$ S. Szatmari and P. F. Schafer, Opt. Commun. 68, 196 (1988).

${ }^{25}$ B. Toftmann, J. Schou, T. N. Hansen, and J. G. Lunney, Phys. Rev. Lett. 84, 3998 (2000).

${ }^{26}$ I. Weaver and C. L. S. Lewis, J. Appl. Phys. 79, 7216 (1996).

${ }^{27}$ CRC Handbook of Chemistry and Physics, 78th ed., edited by D. R. Lide (CRC Press, 1997).

${ }^{28}$ K. Vestentoft and P. Balling, Appl. Phys. A 84, 207 (2006).

${ }^{29}$ J. Byskov-Nielsen, J.-M. Savolainen, M. S. Christensen, and P. Balling, Appl. Phys. A 101, 97 (2010).

${ }^{30} \mathrm{C}$. Wu and L. V. Zhigilei, private communication (2012).

${ }^{31} \mathrm{~B}$. Toftmann and J. Schou, "Time-resolved and integrated angular distributions of plume ions from silver at low and medium laser fluence," Appl. Phys. A (to be published).

${ }^{32}$ B. Doggett and J. G. Lunney, J. Appl. Phys. 109, 093304 (2011).

${ }^{33}$ B. Doggett and J. G. Lunney, J. Appl. Phys. 111, 099902 (2012).

${ }^{34}$ S. Amoruso, R. Bruzzese, X. Wang, N. N. Nedialkov, and P. A. Atanasov, J. Appl. Phys. D 40, 331 (2007).

${ }^{35}$ S. Eliezer, N. Eliaz, E. Grossman, D. Fisher, I. Gouzman, Z. Henis, S. Pecker, Y. Horovitz, and M. Fraenkel, Phys. Rev. B 69, 144119 (2004).

${ }^{36}$ W. Svendsen, O. Ellegaard, and J. Schou, Appl. Phys. A 63, 247 (1996).

${ }^{37}$ E. Millon, J. Perriére, R. M. d'Efourmeau, D. d'Efourmeau, O. Albert, and J. Etchepare, Appl. Phys. A 77, 73 (2003).

${ }^{38}$ Zs. Geretovszky, Z. Kantor, and T. Szörényi, Appl. Surf. Sci. 208-209, 547 (2003). 